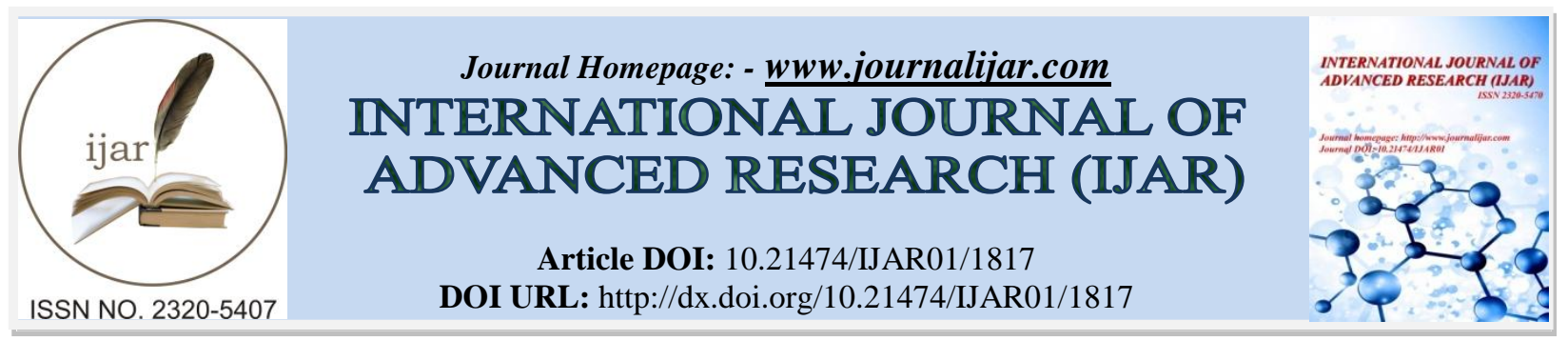

RESEARCH ARTICLE

\title{
A DIRECT METHOD TO OBTAIN AN OPTIMAL SOLUTION IN THE TRANSPORTATION PROBLEM.
}

\section{A. Seethalakshmy ${ }^{1}$ and DR. N. Srinivasan ${ }^{2}$.}

1. Research Scholar, Department of mathematics. St. Peter's university, Avadi, Chennai, India.

2. Professor, Department of mathematics, St. Peter's university, Avadi, Chennai, India

\section{Manuscript Info}

Manuscript History

Received: 12 August 2016

Final Accepted: 23 September 2016

Published: October 2016

Key words:-

Transportation problems, supply,

Demand, Direct method, optimization.

\section{Abstract}

The SS method is a direct method proposed for deriving an optimal solution towards transportation problem. This method solves the problem optimally. Herewith in this research paper, an optimal solution is evinced by row/ column reduction to form a transformed matrix by the systematic allocation of zero by position. Paramount benefit this method produces is lessened the time for calculation, interoperability, and negating degeneracy but not limited to these. Examples herewith make the case for better understanding this method.

Copy Right, IJAR, 2016,. All rights reserved.

\section{Introduction:-}

The special type of linear programming problem is transportation problem. In the transportation problem, there are many origins and many destinations in which the commodities are transported from one place to other in a minimum cost. Each source has a certain amount of the supply and each destination has a certain demand. The objective of this model is to determine the minimized total cost while satisfying all the supply and demand restrictions.

The decision variable $T_{i j}$ of a transportation model the $\mathrm{i}^{\text {th }}$ supply at the source to the $\mathrm{j}^{\text {th }}$ demand at the destination.

Hitchcock first presented this problem in 1941 .For the large scale of the transportation problem; The Simplex method is not suitable. In 1954 Charnes and Cooper had developed Stepping Stone method for the efficiency reason. The initial basic feasible solution was further developed by VAM (Reinfeld and Vogel 1958).

Until now, MODI method was used for obtaining/ solving the transportation problem, this method would be futile without obtaining initial feasibility and degeneracy. Whereas this proposed (SS) method would decapitate the initial feasibility and degeneracy steps thereby leaping to the solution in shortened steps.

The chronology of the events to derive in this method delves as below:-

Section 2 - Presents the mathematical form of TP. Section 3 - Algorithms formulated and Section 4 - Illustrates numerical examples and finally Section 5 - Summarizes with the conclusion and brief discussion of the results.

\section{Mathematical form of transportation problem:-}

The transportation problem can be formulated as an LP problem. Let $T_{i j}, i=1 \ldots . . m, j=1 \ldots . n$ be the number of units transported from source $\mathrm{i}$ to destination $\mathrm{j}$. 
The LP problem is as follows

Minimize $Z=\sum_{i=1}^{m} \sum_{j=1}^{n} K_{i j} T_{i j}$

Subject to the constraints

$\sum_{j=1}^{n} T_{i j} \leq S_{i}$ For all $i$

$\sum_{i=1}^{m} T_{i j} \geq d_{j}$ For all $j$

$X_{i j} \geq 0$

A transportation problem is said to be balanced if

$\sum_{i=1}^{m} S_{i}=\sum_{j=1}^{n} d_{j}$

\section{Sources Destinations}

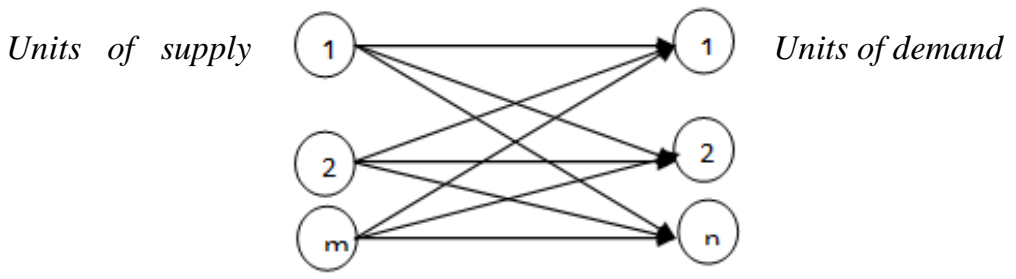

\section{Algorithm:-}

Step 1:-

For the given data construct a transportation table. If the problem is unbalanced, make it as a balanced one.

\section{Step 2:-}

Identify the minimum cost element in each row of the transportation table and subtract in their corresponding row.

\section{Step 3:-}

Similarly, identify the minimum cost element in each column in the resulting table and subtract from their corresponding column

\section{Step 4:-}

Each position of zero is to be discussed Consider the zero of $(\mathrm{i}, \mathrm{j})^{\text {th }}$ position and find the sum of the value in the row and the column for each zero and allocate the minimum of supply/demand for the position of the zero which is having a maximum value. Delete the corresponding row or column where the supply or demand is exhausted.

\section{Step 5:-}

Iterate the table from step 2 to step 4 , till $m+n-1$ cell are allocated and all the supply and demand is exhausted.

\section{Step 6:-}

Calculate the total minimum cost

Total cost $=\sum_{\mathrm{i}=1}^{\mathrm{n}} \sum_{\mathrm{j}=1}^{\mathrm{n}} \mathrm{K}_{\mathrm{ij}} \mathrm{T}_{\mathrm{ij}}$

\section{Note:-}

If there is a tie in maximum value (step 4), give the allocation for the zero position where the supply /demand is minimum. 


\section{Numerical examples:-}

Example.4.1:-

Obtain optimal solution for the given transportation problem

\begin{tabular}{|c|c|c|c|c|c|c|}
\hline & & \multicolumn{4}{|c|}{ Distribution } & \\
\hline \multirow{5}{*}{ 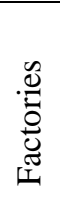 } & & $\mathrm{A}$ & $\bar{B}$ & $\mathrm{C}$ & $\mathrm{D}$ & Supply \\
\hline & $\mathrm{S}_{1}$ & 10 & 2 & 20 & 11 & 15 \\
\hline & $\mathrm{S}_{2}$ & 12 & 7 & 9 & 20 & 25 \\
\hline & $\mathrm{S}_{3}$ & 4 & 14 & 16 & 18 & 10 \\
\hline & Req & 5 & 15 & 15 & 15 & 50 \\
\hline
\end{tabular}

Step 1:-

After Row reduction and column reduction

\begin{tabular}{|c|c|c|c|c|c|c|}
\hline & & \multicolumn{4}{|c|}{ Distribution } & \\
\hline \multirow{5}{*}{ 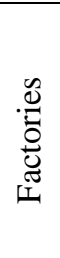 } & & $\bar{A}$ & B & $\mathrm{C}$ & $\mathrm{D}$ & Supply \\
\hline & $S_{1}$ & 8 & 0 & 16 & 0 & 15 \\
\hline & $\mathrm{S}_{2}$ & 5 & 0 & 0 & 4 & 25 \\
\hline & $\mathrm{S}_{3}$ & 5 & 10 & 10 & 5 & $\begin{array}{c}T Q \\
5\end{array}$ \\
\hline & Req. & 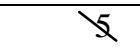 & 15 & 15 & 15 & \\
\hline
\end{tabular}

Step 2:-

After Row reduction and column reduction

\begin{tabular}{|c|c|c|c|c|c|}
\hline \multirow{4}{*}{} & & $\mathrm{B}$ & $\mathrm{C}$ & $\mathrm{D}$ & Supply \\
\cline { 2 - 6 } & $\mathrm{S}_{1}$ & 0 & 16 & 0 & 15 \\
\cline { 2 - 6 } & $\mathrm{S}_{2}$ & & 15 & & 25 \\
\cline { 2 - 6 } & & 0 & 0 & 4 & 10 \\
\cline { 2 - 6 } & $\mathrm{S}_{3}$ & 5 & 5 & 15 & 5 \\
\cline { 2 - 6 } & Req. & 15 & $\mathrm{~N}$ & 0 & \\
\hline
\end{tabular}

Step 3:-

After Row reduction and column reduction

\begin{tabular}{|c|c|c|c|c|c|c|}
\hline \multirow{4}{*}{ 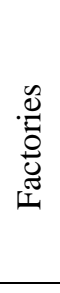 } & & & B & & $\mathrm{D}$ & Supply \\
\hline & $\mathrm{S}_{1}$ & 5 & 0 & 10 & 0 & 15 \\
\hline & $\mathrm{S}_{2}$ & 10 & 0 & & 4 & 10 \\
\hline & $\mathrm{S}_{3}$ & & 5 & 5 & 0 & 5 \\
\hline & Req. & & 15 & & 15 & \\
\hline
\end{tabular}

\section{Step 4:}

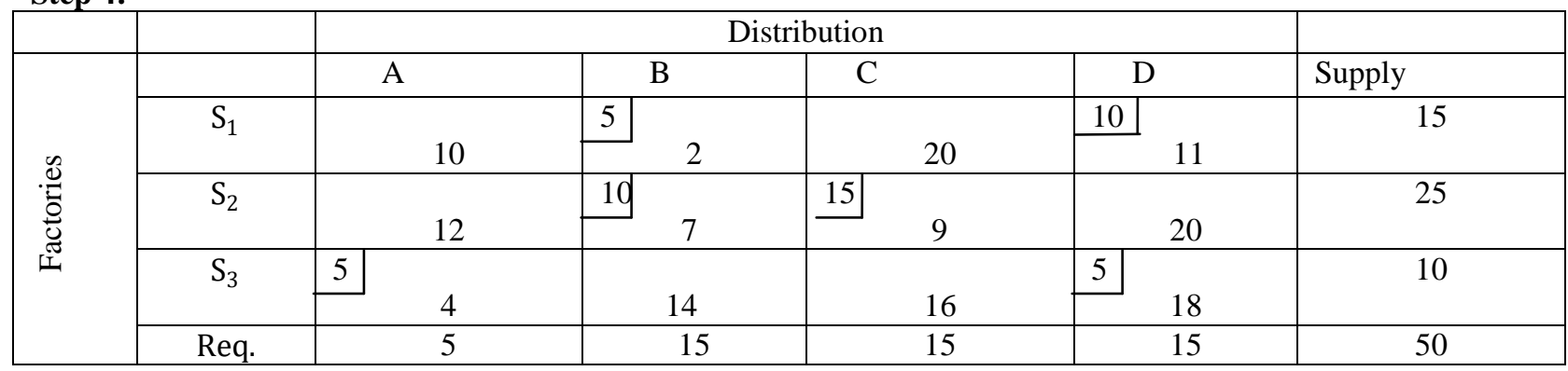

$$
\text { [m }+\mathrm{n}-1=3+4-1=6 \text { allocation] }
$$

Minimum cost $=5 \times 2+10 \times 11+10 \times 7+15 \times 9+5 \times 4+5 \times 18$

Minimum cost $=\mathbf{4 3 5}$ 


\section{COMPARISON CHART}

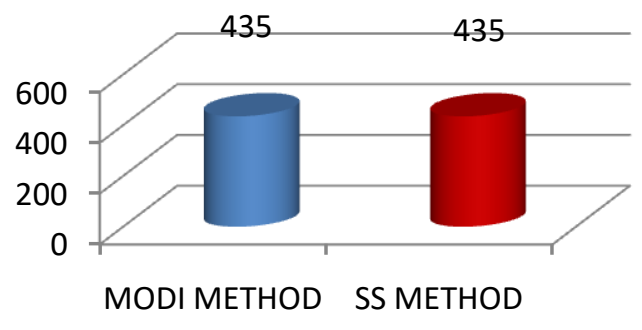

Example 4.2:-

A company has three factories and four distribution centers.

\begin{tabular}{|c|c|c|c|c|c|c|}
\hline & & \multicolumn{4}{|c|}{ Distribution } & \multirow[b]{2}{*}{ Supply } \\
\hline \multirow{5}{*}{$\frac{\mathscr{n}}{\stackrel{0}{0}}$} & & Madras & Madurai & Trichy & Salem & \\
\hline & $\mathrm{S}_{1}$ & 3 & 2 & 7 & 6 & 5000 \\
\hline & $\mathrm{S}_{2}$ & 7 & 5 & 2 & 3 & 6000 \\
\hline & $\mathrm{S}_{3}$ & 2 & 5 & 4 & 5 & 2500 \\
\hline & Req. & 6000 & 4000 & 2000 & 1500 & \\
\hline
\end{tabular}

Suggest the optimal transportation schedule and find the minimum cost of transportation.

\section{Step 1:-}

After Row reduction and column reduction.

\begin{tabular}{|c|c|c|c|c|c|c|}
\hline & & Distributio & & & & \\
\hline \multirow{6}{*}{ 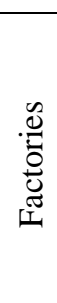 } & & Madras & Madurai & Trichy & Salem & Supply \\
\hline & $\mathrm{S}_{1}$ & 1 & 0 & 5 & 3 & 5000 \\
\hline & \multirow[b]{2}{*}{$\mathrm{S}_{2}$} & \multirow[b]{2}{*}{5} & \multirow[b]{2}{*}{3} & \multirow[b]{2}{*}{0} & 1500 & \multirow{2}{*}{$\begin{array}{l}600 \theta \\
400 \theta \\
2500\end{array}$} \\
\hline & & & & & 0 & \\
\hline & $\mathrm{S}_{3}$ & 0 & 3 & 2 & 2 & 2500 \\
\hline & Req. & 6000 & 4000 & $200 \theta$ & 1500 & \\
\hline
\end{tabular}

Step 2:-

After Row reduction and column reduction.

\begin{tabular}{|c|c|c|c|c|}
\hline \multirow{5}{*}{ 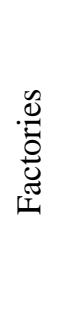 } & & Madras & Madurai & Supply \\
\hline & $\mathrm{S}_{1}$ & 1 & 0 & 5000 \\
\hline & $\mathrm{S}_{2}$ & 2 & 0 & 2500 \\
\hline & $\mathrm{S}_{3}$ & 2500 & 3 & -590 \\
\hline & Req. & $\begin{array}{l}600 \theta \\
3500\end{array}$ & 4000 & \\
\hline
\end{tabular}

Step 3:-

After Row reduction and column reduction.

\begin{tabular}{|c|c|c|c|c|}
\hline \multirow{5}{*}{ 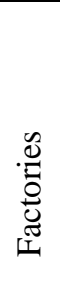 } & & Madras & Madurai & \multirow{2}{*}{$\frac{\text { Supply }}{500 \theta}$} \\
\hline & \multirow[t]{2}{*}{$\mathrm{S}_{1}$} & \multirow{2}{*}{0} & 1500 & \\
\hline & & & 0 & 3500 \\
\hline & $\mathrm{S}_{2}$ & 2 & 2500 & $250 \theta$ \\
\hline & Req. & 3500 & $\begin{array}{l}400 \theta \\
150 \theta\end{array}$ & \\
\hline
\end{tabular}




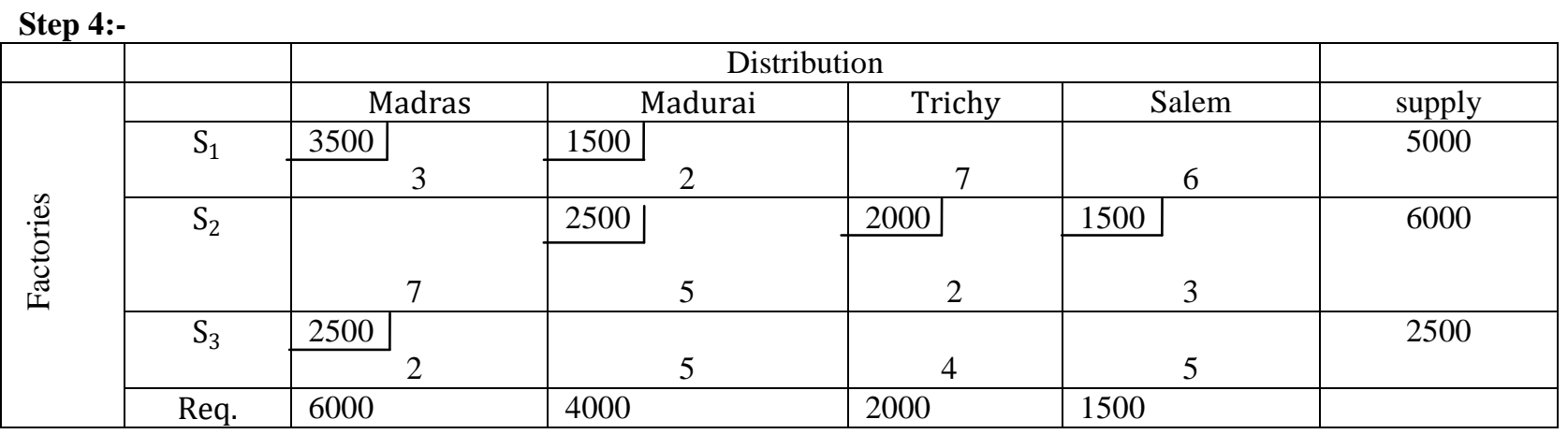

$[\mathrm{m}+\mathrm{n}-1=3+4-1=6$ allocation $]$

Minimum cost $=3500 \times 3+1500 \times 2+2500 \times 5+2000 \times 2+1500 \times 3+2500 \times 2$

Minimum cost $=\mathbf{3 9 , 5 0 0}$

\section{Conclusion:-}

A direct method proposed here solves the transportation problem. This method can be applied to all transportation problems and its kind.SS algorithm contains a systematic procedure, easy to comprehend. Here a maximum value of the sum of row and column of the zero's are given allocation. This (SS) method aids in decision- making process and stands out in comparison to other methods given its quick steps with tangible solutions.

\section{References:-}

1. H.A.Taha, Operations Research-Introduction, Prentince hall of India New Delhi, $8^{\text {th }}$ edition 2007.

2. J.K.Sharma, Operations Research-Theory and Application, Macmillian India LTD, New Delhi-2005.

3. P.K.Gupta ,D.S Hira, Operation Research, S. Chand \& Company Limited, $14^{\text {th }}$ Edition 1999.

4. N.Srinivasan D.Iraninan, A new approach for solving assignment problem with optimal solution, International journal of Engineering and management research, Volume 6 Issue -3 May - June 2016.

5. V.J.Sudhakar,N. Arunsankar,T.Karpagam 'A new approach for finding an optimal solution for TP, European Journal of Scientific Research, ISSN 1450-216x vol.68 No 2(2012) pp.254- 257

6. P.Pandian and G. Natarajan' a new method for finding an optimal solution for TP, International Journal of Math Science and Engineering. Appls(IJMSEA),4(2010) 59-65

7. N.M.Deshmukh 'An innovative method for solving TP- International Journal of Physics and Mathematical Sciences ISSN: 2277-2111.2012 Vol.2 (3) July-Sep pp:86-91.

8. Kirca and Stair1990. A heuristic for obtaining an initial solution for transportation problem- Journal of operational Research Society, 41:865-867

9. Smita sood and Keerti Jain, The maximum difference method to find initial basic feasible solution for transportation problem-Asian Journal of Management Sciences, 03[07] 2015:8-11

10. Gauss, S.I, On solving the transportation problem, Journal of Operational Research Society 41(4)(1990) 291297. 